\title{
UCRL-TR-233538
}

LAW RENCE LIVERMORE N A TIO NAL LABORATORY

Double Difference Earthquake Locations at the Salton Sea Geothermal Reservoir

K. L. Boyle, L. J. Hutchings, B. P. Bonner, W.

Foxall, P. W. Kasameyer

August 9, 2007 
This document was prepared as an account of work sponsored by an agency of the United States Government. Neither the United States Government nor the University of California nor any of their employees, makes any warranty, express or implied, or assumes any legal liability or responsibility for the accuracy, completeness, or usefulness of any information, apparatus, product, or process disclosed, or represents that its use would not infringe privately owned rights. Reference herein to any specific commercial product, process, or service by trade name, trademark, manufacturer, or otherwise, does not necessarily constitute or imply its endorsement, recommendation, or favoring by the United States Government or the University of California. The views and opinions of authors expressed herein do not necessarily state or reflect those of the United States Government or the University of California, and shall not be used for advertising or product endorsement purposes.

This work was performed under the auspices of the U.S. Department of Energy by University of California, Lawrence Livermore National Laboratory under Contract W-7405-Eng-48. 


\section{Double Difference Earthquake Locations at the Salton Sea Geothermal Reservoir}

Katie Boyle, Lawrence Hutchings, Brian Bonner, Bill Foxall, and Paul Kasameyer Lawrence Livermore National Laboratory, P.O. Box 808, Livermore, CA 94551

\section{Abstract}

The purpose of this paper is to report on processing of raw waveform data from 4547 events recorded at 12 stations between 2001 and 2005 by the Salton Sea Geothermal Field (SSGF) seismic network. We identified a central region of the network where vertically elongated distributions of hypocenters have previously been located from regional network analysis. We process the data from the local network by first autopicking first $\mathrm{P}$ and $\mathrm{S}$ arrivals; second, improving these with hand picks when necessary; then, using cross-correlation to provide very precise $\mathrm{P}$ and $\mathrm{S}$ relative arrival times. We used the HypoDD earthquake location algorithm to locate the events. We found that the originally elongated distributions of hypocenters became more tightly clustered and extend down the extent of the study volume at $10 \mathrm{Km}$. However, we found the shapes to depend on choices of location parameters. We speculate that these narrow elongated zones of seismicity may be due to stress release caused by fluid flow.

\section{Introduction}

The purpose of this project is to utilize the more than 10 years of passive earthquake recordings available from CalEnergy, Calipatria, CA to interpret the geologic structure and constituent properties within and below the Salton Sea Geothermal Field. We have obtained raw waveform data from 4547 events recorded at 12 stations between 2001 and 2005 by the Salton Sea Geothermal Field (SSGF) seismic network. We have also obtained data from over 200 events recorded at 16 stations from September 15, 1987 to January 05, 1988 by Lawrence Livermore National Laboratory, and 3D Seismic refraction data also obtained from CalEnergy. The purpose of this paper is to report on the quality of the data, processing, outline for future analyses, and provide preliminary HypoDD event locations. We have focused on the central portion of the study area where, previously, events located with cross-correlation in a joint hypocenter determination with the regional Imperial Valley Network (Shearer et at., 2005, personal communication) revealed an elongated vertical distribution of hypocenters (Figure 1a). Figure 1b shows epicentral locations, station locations for this study, and the study area. We expect that the local SSGF seismic network will illuminate the fine detail of these event locations.

a)

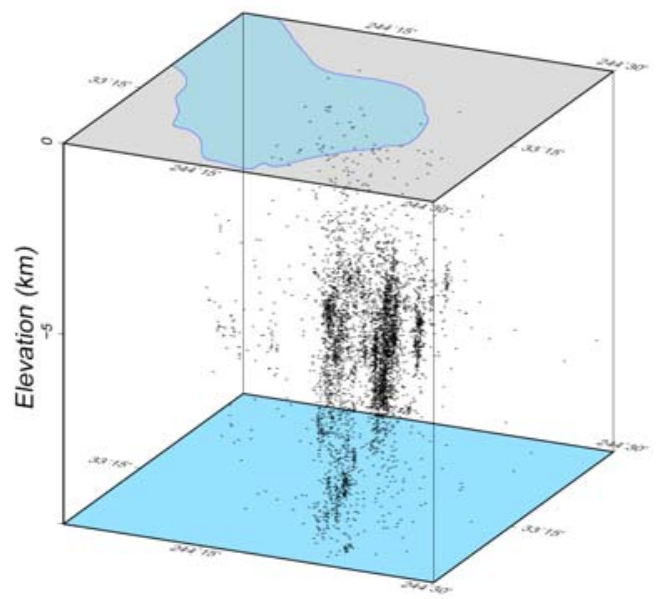

b)

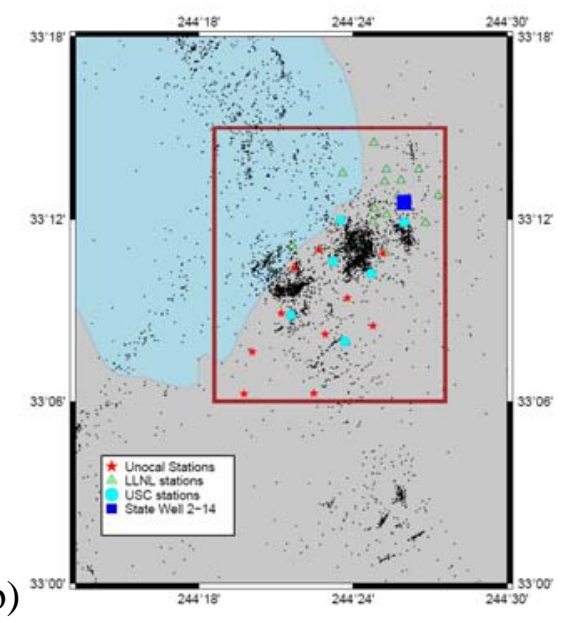

Figure 1. a) 3-D view of study area showing events located by Shearer et al (2005); b) study area, recording stations and event locations. 


\section{Geology}

The Salton Sea Geothermal System lies in the southeastern shore of the Salton Sea, a lake whose surface is $68 \mathrm{~m}$ below sea level. The Salton Sea is the lowest part of the Salton Trough, a tectonic depression. The Trough is an active rift between the Pacific and North American plates, and formed between 4 and $5 \mathrm{Ma}$. As the rift opens, mafic intrusive rocks fill it from below as sedimentary rocks fill in from above. The prograding delta of the Colorado River has isolated this depression from the Gulf of California, to the south, forming a closed basin. Diversion of the River exclusively into the Trough rather than the Gulf supplied large amounts of water and sediments. As a result the modern Trough is filled by up to $6 \mathrm{~km}$ of siliciclastic, fluvial and lacustrine mudstone, siltstone, and sandstone (Hulen et al., 2003; Elders and Sass, 1988). Rifting and intrusions produce high heat flow that metamorphoses the sedimentary rocks to shallow depths (Fuis et al., 1984).

The Trough has steep, step-faulted margins and a broad, relatively flat basement floor at about 6 $\mathrm{km}$ depth. The metasedimentary "upper basement" persists to a depth of 10-16 km and is underlain by a "lower basement" with seismic properties and densities similar to those of oceanic crust (Fuis et al., 1984)

\section{Data Processing}

The Cal Energy array consists of 12 recording stations: five 1-component stations and seven 3component stations. We have combined auto-picks and hand picks for both $\mathrm{P}$ and $\mathrm{S}$ waves with cross-correlation to provide very precise relative $\mathrm{P}$ and $\mathrm{S}$ arrival times. We reviewed auto-picks by eye and modified them as necessary before performing cross-correlation. Travel time data is used here to obtain precise relative earthquake locations in the central portion of the study area using the HypoDD earthquake location program. In the future, we will use travel times, pulse widths, and spectral estimates to obtain tomographic velocity and Q profiles and stress distribution throughout the reservoir. We will combine this with rock physics interpretations (Bonner et al., 2006) to identify permeability zones and help identify drilling targets for geothermal production-well drilling.

We have automated several parts of the data processing steps to allow management of large amounts of data. Figure 2 shows the sequence of data processing, computer runs, and analysis that will be applied to this project. On the left, and going down, we start with raw data and convert to SAC format. We then identify events with signal to noise ratio (SNR) for P-waves > 10:1 at at least 7 stations and SNR $>5: 1$ for S-waves at at least 5 stations. We then used the autopicking algorithm piki.f to identify both $\mathrm{P}$ and $\mathrm{S}$ arrival times on the high-quality records. Column two shows several computer programs that develop meta-data for final analysis. First, we run hypoinverse to generate a first estimate of the earthquake locations. Then, we identify events that are located close together so that we can perform a cross-correlation analysis to further improve $\mathrm{P}$ and $\mathrm{S}$-wave relative arrival times. We also measure pulse widths at this point to provide time domain estimates of $t^{*}$. We then use the arrival times and locations to run program HypoDD (Waldhauser and Ellsworth 2000) to obtain precise relative earthquake locations. We then us program NetMoment (Hutchings, 2002) along with HypoDD locations and recorded spectra to get spectral estimates of $t^{*}$ and stress drop. Column three shows the primary imaging programs that provide the basis for final analysis: SimulPS (Thurber, 1983) and tomoDD (Zang, 2003) for velocity structure, SimulQ (Zucca et al., 1993) for Q structure. The 
fourth column shows the data that will be obtained from these programs and used for the analysis.

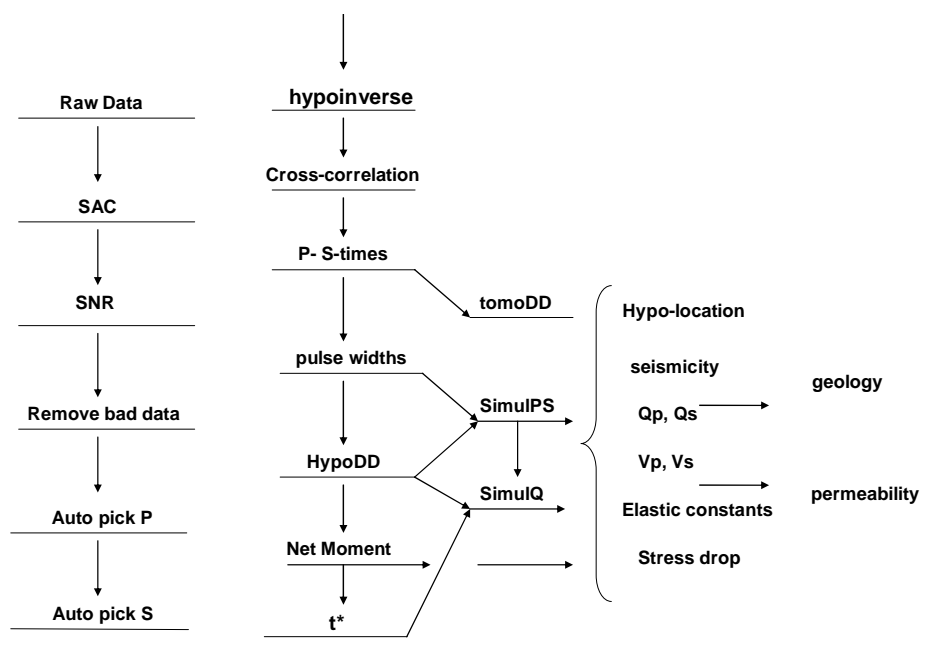

Figure 2. Data processing and programs to provide analysis of permeability.

Figures 3 and 4 show auto P- and S-wave auto picks for two different events at a particular station. The captions explain the differences between picks.

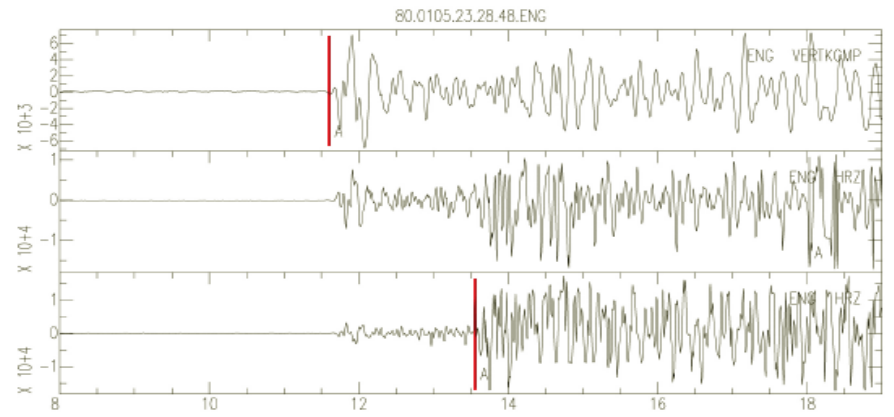

Figure 3. Auto P- and S-wave picks. S-waves were only identified on one component.

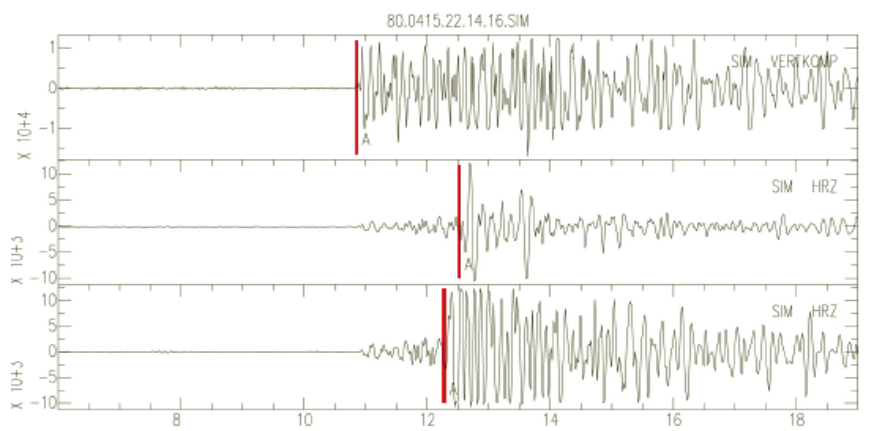

Figure 4. Auto P- and S-wave picks. When S-pick times differ, the highest confidence pick is used. The differential S-wave times will be used to identify possible shear-wave splitting. 
If the two events are located close to each other relative to their inter-station distance, and are approximately the same size, then their waveforms should be nearly identical due to nearly identical travel paths. We use this similarity in waveforms to adjust the auto P-picks with crosscorrelation. Figure 5 shows an improved P-pick. The waveforms are not exactly identical, but are similar enough that the cross-correlation technique is able to improve the picks. The crosscorrelation value is 0.90. Bad cross-correlation picks occur when events are not located near each other, have different focal mechanism solutions (Hutchings and $\mathrm{Wu}, 1990$ ), or where noise dominates the cross-correlation calculation.

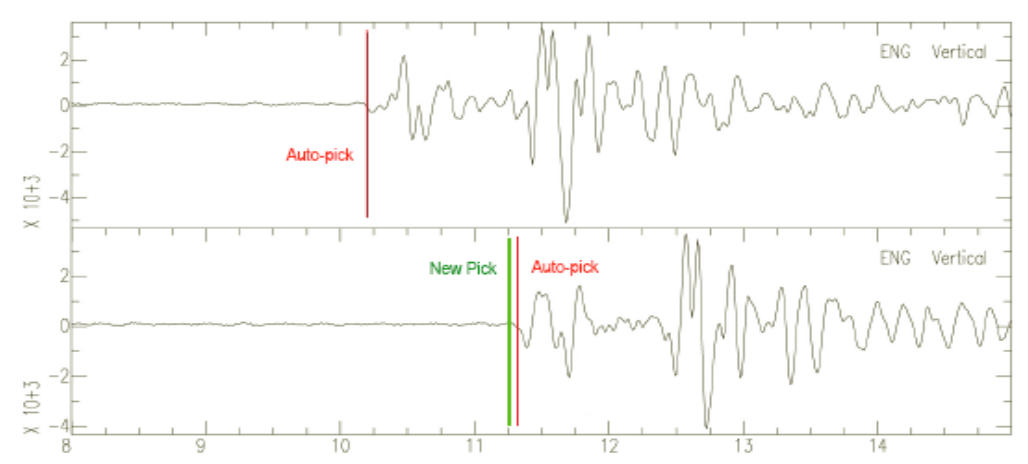

Figure 5. Using cross-correlation to improve P-pick.

\section{Double Difference Earthquake Locations}

The selected events were first located with Hypoinverse, using the Salton Sea velocity model of Holland (2003). Holland obtained the velocity model by a one-dimensioanl inversion of the 1987 and 1988 LLNL data. Of the 1081 high quality events, only 862 were successfully located by Hypoinverse. These locations are shown in Figure 6. Comparison between Figure 1b and 6b

(a)

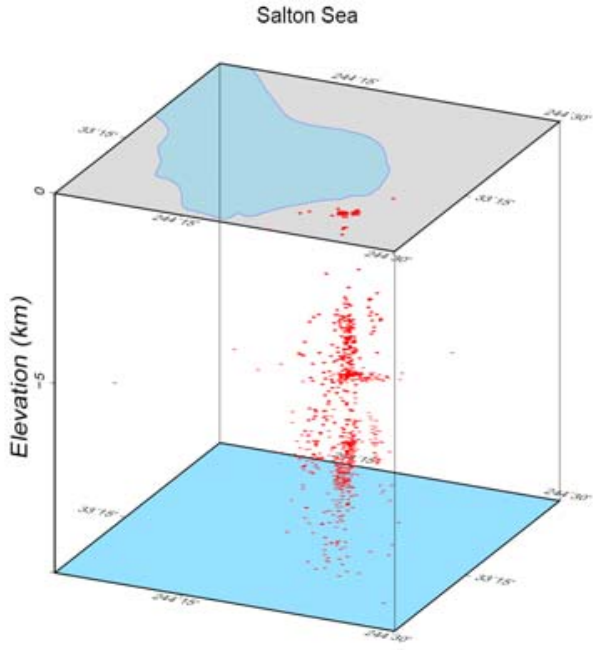

(b)

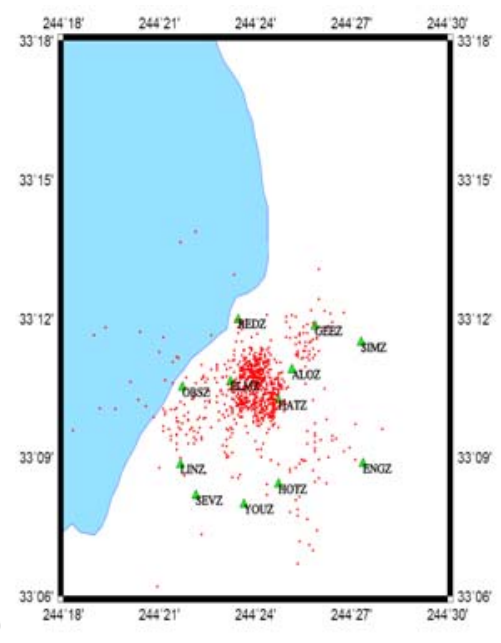

Figure 6. Hypoinverse locations (red) in 3-D (a) and 2-D views (b). 
shows that the locations from this study are shifted about $1 \mathrm{~km}$ south from Shearer's locations. Also, the third cluster of Shearer's events, in the southwest, is relatively more dense than the events shown in Figure 6b. This may be an artifact, since we did not try to locate every event. Rather, we applied a very strict selection criteria and the better stations were near the center cluster [ELMZ (3-comp), ALOZ (3-comp), and HATZ (1-comp)]. Therefore nearby events get more arrivals that pass the selection criteria. It also should be noted that most of the events recorded at station ALOZ showed P-wave expression on one horizontal component, and S-wave expression on the other horizontal and the vertical component. This is likely due to a network processing error.

In the Figure 6a, we see a gap in seismicity at around the 5-km depth, with two cylindrical groups of events above and below the zone. This is important to note, since relocation with HypoDD is sensitive to events that are inter-related in space. Also note the small grouping of shallow events at the top of Figure 6a. These events would be expected to manifest P-arrivals minimally on the vertical component, which may explain the strange results seen at ALOZ.

The 862 events located by Hypoinverse were first grouped into phase pairs using the HypoDD utility ph2dt. This program calculates and summarizes the differential arrival times for each pair of events at each station. Ph2dt used user-defined parameters to form event pairs, links, nearest neighbor networks, and eventually entire clusters containing events whose locations will all be derived from a simultaneous double-difference calculation for location relative to every other event in the cluster. Considering this, the highest quality results will be obtained by making the cluster as large as possible, while minimizing the distance between paired events. We also need to establish a minimal level of double-difference observations per pair before we consider that pair to contain "strongly" linked neighbors. These parameters are defined in the input file ph2dt.inp. The parameters we felt would best optimize our data set are: MINWGHT =0, MAXDIST=50, MAXSEP=5, MAXNGH=250, MINLINK=4, MINOBS=8, MAXOBS=12.

Four parameters were held constant over all trials - these were MINWGHT, MAXDIST, and MINLNK. To ensure that we are considering all available phase pairs, we set the minimum location weight (MINWGHT) for each pair to 0 , the lowest confidence. We allow a maximum distance of $50 \mathrm{~km}$ between any event pair and its respective recording stations (MAXDIST) because we are seeking a very small intra-event distance between paired events relative to the distance between the pair and recording station. Finally, neighbors with less than MINLNK phase pairs are considered "weak neighbors" while event pairs with more than MINOBS phase pairs are considered "strong neighbors." MAXOBS is the maximum number of common recording stations for each event pair, and thus can only be as large as the number of stations, 12.

The three remaining parameters were varied frequently over trials. The HypoDD relocation process works best when events are randomly located within the search radius. From Hypoinverse, it's apparent that our events map out a complexly shaped set of clouds, and so we need to be careful in our selection of MAXSEP, the maximum separation between paired events. To keep the double-difference calculations from exceeding the capacities of HypoDD's arrays, and the memory of our computer, we need to define the MAXNGH, the upper limit of stronglylinked pairs that we will choose within the radius defined by MAXSEP. In order for the results to be as precise as possible, MINOBS should be set to 8 to cover all 8 degrees of freedom in hypocentral location (4 degrees of freedom per earthquake), but this parameter can also be set to 1 to ensure that all available phase pairs are selected. 
Once this file has been fed into ph2dt along with phase output from Hypoinverse, the program works to generate tables of event pairs and their common recording stations. The output of ph2dt is 4 files: event.dat, which lists every input event, event.sel, which lists only the events that are clustered according to the criteria described above, dt.ct, which lists the phase pairs and differential travel times for catalog locations, and dt.cc, which lists the phase pairs and relative lag time for cross-correlated events. These four files become input for the HypoDD program. The same parameters discussed in ph2dt.inp re-appear in hypoDD input file, but we can further constrain them to optimize our data set. We also have control over the weighting and reweighting schemes performed during each iteration of the double-difference calculations. We used liberal selection criteria when pre-screening the events with ph2dt, but with HypoDD we wanted to ensure the highest accuracy possible with our final event locations.

\section{Selection of HypoDD Parameters}

After running 30-40 trials, varying key parameters each time, we discovered that HypoDD solutions must be evaluated from a number of viewpoints, with a thorough investigation of the meaning of each parameter, and with certain open-mindedness toward the variability of the outcomes. We discovered four general clustering patterns that emerged from the HypoDD relocation of our 862 events. However, the shapes of the clusters depend upon the selection of parameters. Below, we chose a representative result from each clustering type, and discuss the possible parameter values that led to each. The lack of events extending to the depths observed with Hypoinvers locations (Figure 6) is due to events not meeting selection criteria.

\section{Run 22.}

For this run, we maximized the number of events used in the double-difference process by making both MAXNGH and MAXSEP large. MAXNGH was set to 250 events and MAXSEP was set to 7 kilometers, much larger than the short axis of the event ellipsoids shown in Figure 8, but smaller than the long axis of these ellipsoids. We set MINOBS to 1, to include all available phase pairs. Remember that MINOBS is the minimum number of common stations per event pair, and optimally should be set to 8 to cover all 8 degrees of freedom for the two events.

The authors of HypoDD explain that ph2dt should be used to produce as many pairs as possible, and the refinement of pairs should be done in the input file hypoDD.inp. It is here that we set OBSCC and OBSCT equal to 4, meaning that all cross-correlation and catalog pairs must have at least 4 common stations. We choose the method of Least Squares to calculate the doubledifference locations, and we remain fairly liberal in our selection of weighting and residual criteria. Again, the aim of this run is to see what happens when the number of clustered events is MAXIMAL, regardless of quality criteria. The results of Run 22 are shown in Figure 7.

(a)

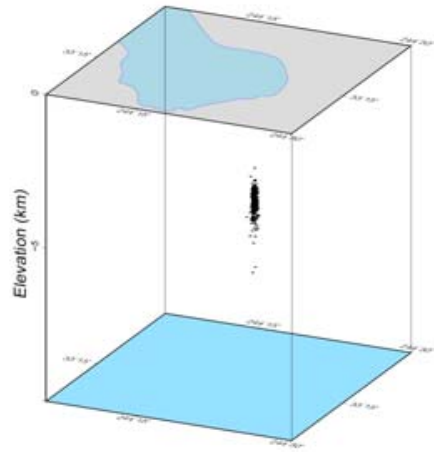

(b)

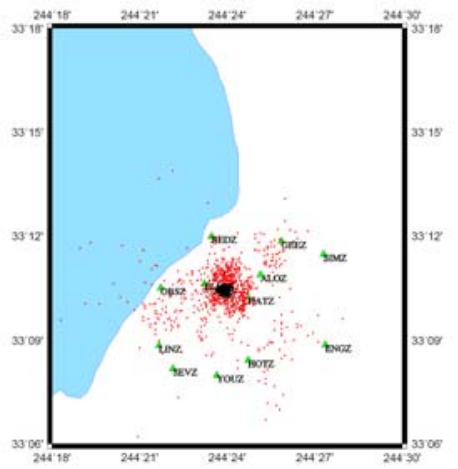

Figure 7. Run 22. Notice the "bullseye" appearance of the HypoDD events (black) 


\section{Run 25.}

For this run, we maximized the number of event pairs by using the same liberal criteria for ph2dt as listed above, but our HypoDD residual criteria were more restrictive. We halved the allowed inter-event distance for cross-correlated pairs from $1 \mathrm{~km}$ to $0.5 \mathrm{~km}$, and shrunk the residual threshold from $0.5 \mathrm{~s}$ to $0.1 \mathrm{a}$. We reduced the residual threshold for catalog pairs from $1 \mathrm{~s}$ to $0.2 \mathrm{~s}$. The results are shown in Figure 8.

(a)

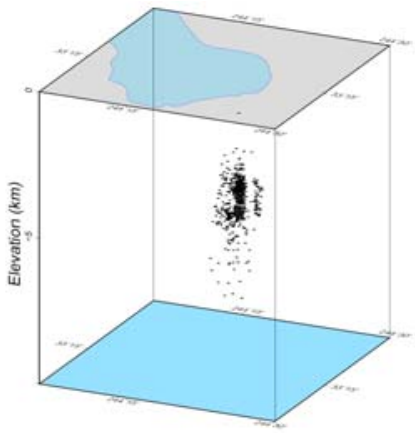

(b)

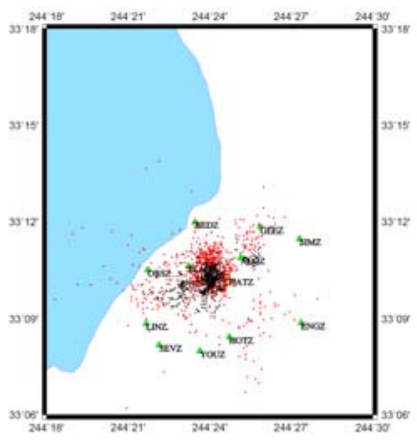

Figure 8. Run 25. Note the two distinct clusters present in the 3-D view (a), and the compaction of the cluster's extent in the 2-D view (a), with HypoDD locations (black) being confined to a much smaller radius than Hypoinverse locations (red).

\section{Run 17.}

This run represents more conservative clustering, with MAXSEP being changed from $7 \mathrm{~km}$ to $5 \mathrm{~km}$. This means that the events meeting our criteria are generally closer to each other in space, and should lead to an overall reduction in model errors for longer traveled distances.

Additionally, two different sets of weighting and residual criteria were applied to the first 4 iterations, which these criteria being broad and forgiving. This corresponds to a smaller group of paired events, but a lot of leeway for double-difference locations within that group. These are shown in Figure 9. Notice that the "bulls eye" has moved about $2 \mathrm{~km}$ to the northwest. This suggests a systematic bias we do not yet understand. Also, there is small-scale and local clustering that results from intensive weighting and reweighting during the first 4 iterations. Since these iterations contribute the largest net movement of individual events, large steps were taken in the beginning and may account for the systematic shift in event locations.

(a)

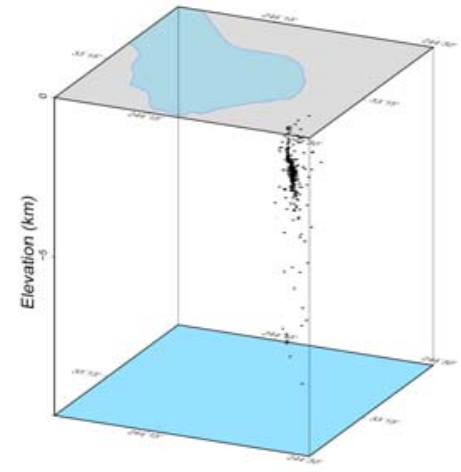

(b)

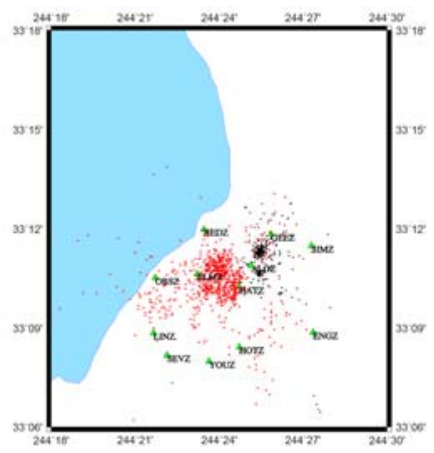

Figure 9. Run 17. Notice the distinctively systematic shift in location and smaller number of events (b) and the resulting emergence of delicate linear features in 3-D view (a). 


\section{Run 26.}

This run was meant to search for the most accurate locations possible. This was done by reducing MAXSEP to 4km so that we could increase MAXNGH to 300 events. This is the largest value for MAXNGH that our computers could handle with their current RAM. "Large scale” HypoDD problems require 1.4G of RAM, while our computer RAM tops out at 1.0G. We also set MINOBS to 4, when it had been 1 for all other trials. In the hypoDD input file, we set OBSCC and OBSCT to 8, meaning that each cross-correlation and catalog pair must share 8 common recording stations. While this grossly diminishes the number of events in the cluster, it assures that only the most high quality recordings are being used. This means that the double difference locations are being performed between a subset of high Signal-to-Noise, high magnitude, high quality events. These are shown in Figures 10 and 11.

(a)

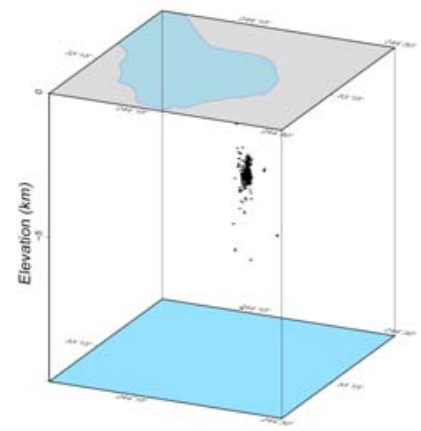

(b)

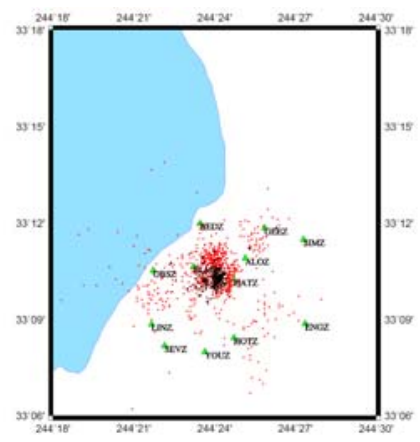

Figure 10. Run 26. Notice the petite dimensions of the surviving cluster, and the small number of earthquakes.

The complexity of small-scale features are visible upon rotation, Figure 11.

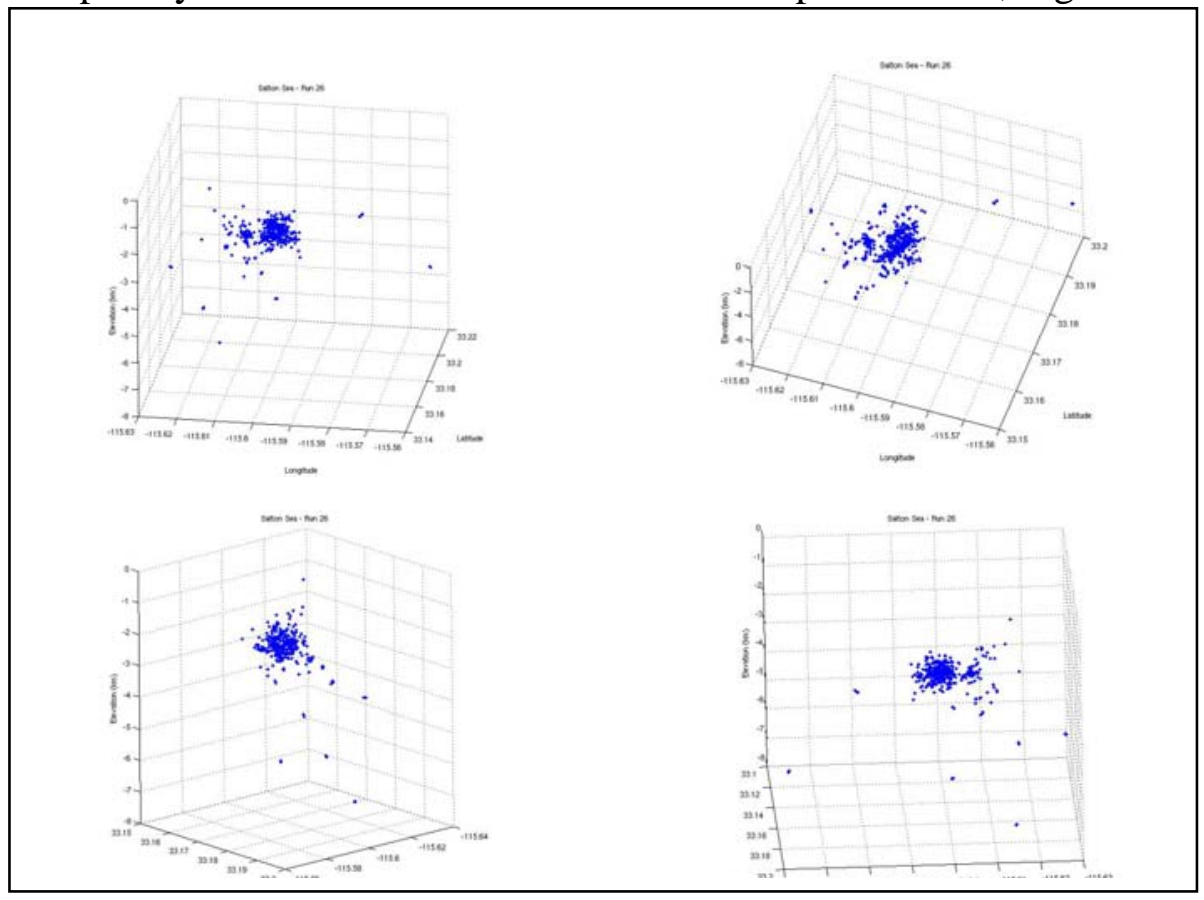

Figure 11. Notice the complexity of small-scale features visible upon rotation. 
Because of the considerable variation in the dimensions and location of our re-located events, we cannot conclude anything decisive about the shape or orientation of our cluster. In order to set ourselves up for the most telling results, we need to use a more powerful computer so that we can push MAXNGH to 862 (the total number of events), MAXSEP to 7 (the upper bound on the intra-event distances for our pairs), and MINOBS to 1(to ensure that all phase pairs are selected).

By considering the effects of parameter variation on the whole, we can conclude a few general ideas about the dimensions of the swarm. A number of features were found in common across all 4 of these distinct configurations. First, the top of each cluster was located at or around 2-3km of depth. Second, all clusters showed extension along the vertical axis, and shortening along the horizontal axes. Third, each cluster appeared to have a large mass of earthquakes separated by a few kilometers from a smaller proximal mass of events. This separation was found in all 4 examples above. All clusters appeared to have planar and linear features, and there appears to be a broad plane of "action" present in all 4 configurations.

\section{Conclusions}

Based on the set of 862 events that have been located with HYPOINVERSE and further refined with HypoDD, there appears to be a tubular geologic feature extending downward to at least 5 $\mathrm{km}$ in the southeast corner of the Salton Sea geothermal study area. We found that the fine detail of this distribution is dependent upon parameters selected for programs ph2dt and HypoDD. We have yet been able to determine which interpretation is preferred. However, we expect that we need to use a more powerful computer so that we can push MAXNGH to 862, MAXSEP to 7, and MINOBS to 1 . However, we will also be investigating whether the variations we observed in HypoDD locations is the uncertainty in accuracy that can be obtained from the program. Finally, we found that the originally elongated distributions of hypocenters became more tightly clustered and extend down the extent of the study volume at $10 \mathrm{Km}$. However, we found the shapes to depend on choices of location parameters. We speculate that these narrow elongated zones of seismicity may be due to stress release caused by fluid flow. This may be a result of localized pore pressure increase that might allow the faults to slip in this region.

\section{References}

Berge, Patricia, Lawrence Hutchings, Jeffrey Wagoner, and Paul Kasameyer (2001). Rock Physics Interpretation of P-wave Q and Velocity Structure, Geology, Fluids and Fractures at the Southeast Portion of The Geysers Geothermal Reservoir. Geothermal Res. Council, Transactions, 14, Annual Meeting, San Diego, CA.

Bonner, B., L. Hutchings and P. Kasameyer (2006). A Strategy for Interpretation of Microearthquake Tomography Results in the Salton Sea Geothermal Field Based upon Rock Physics Interpretation of State 2-14 Borehole Logs. Geothermal Resources Council, LLNL, UCRL-PROC-222141.

Elders, W.A., and J.H. Sass, 1988. “The Salton Sea Scientific Drilling Project. J. Geophys. Res. v. 93, No. B11, p. 12,953-12,968.

Fuis, G.S., W.D. Mooney, J.H. Healey, G.A. McMechan, and W.J. Lutter (1984) A Seismic Reflection Survey of the Imperial Valley, California. Journal of Geophysical Research, 89, 11651189. 
Hauksson, E. and P. Shearer, Southern California hypocenter relocation with waveform crosscorrelation, Part 1: Results using the double-difference method, Bull. Seismol. Soc. Am., 95, 896-903, doi:10.1785/0120040167, 2005.

Holland, Austin A. (2002) Microearthquake Study of the Salton Sea Geothermal Field, California: Eviodence of Stress Triggering. Idaho National Engineering and Environmental Laboratory, Geosciences Department. Thesis, The University of Texas at El Paso, May 2002.

Hutchings, L. and Wu, F. (1990) Empirical Green's Functions from Small Earthquakes: A Waveform study of Locally Recorded Aftershocks of the 1971 San Fernando Earthquake. J Geophys Res, 95, 1187-1214.

Hutchings, Lawrence (2002) Program NetMoment, a Simultaneous Inversion for Moment, Source Corner Frequency, and Site Specific t*. Lawrence Livermore National Laboratory, UCRL-ID 135693.

Hole, J.A. and B.C. Zelt (1995) 3-D finite-difference reflection travel times. Geophys J Int 121, 427-434.

Hulen, Jeffrey, Dennis Kaspereit, Denis L. Norton, William Osborn, and Fred S. Pulka (2002) Refined Conceptual Modeling and a New Resource Estimate for the Salton Sea Geothermal Field, Imperial Valley, California. Geothermal Resources Council Transactions, Vol. 26, September 22-25.

Shearer, P., E. Hauksson and G. Lin (2005). Southern California hypocenter relocation with waveform cross-correlation, Part 2: Results using source-specific station terms and cluster analysis, Bull. Seismol. Soc. Am., 95, 904-915.

Thurber, C.H. (1983). Earthquake locations and three-dimensional crustal structure in the Coyote Lake area, central California. J. Geophys. Res., 88, 8226-8236.

Waldhauser, F., \& W.L. Ellsworth (2000). A double-difference earthquake location algorithm: Method and applications to the northern Hayward fault. Bull. Seism. Soc. Am., 90, 1353-1368.

Zhang, H. (2003) Double-difference Seismic Tomography Method and its Applications. Ph.D. dissertation, University of Wisconsin-Madison.

Zucca, J.J., Hutchings, L.J., \& Kasameyer, P.W. (1994). Seismic Velocity and Attenuation Structure of the Geysers Geothermal Field, California. Geothermics, 23, 111-126.

\section{Acknowledgments}

This work is funded by the California Energy Commission, contract PIR-04-004, in collaboration with CalEnergy, Operating Company, Calipatria, CA. We appreciate the enthusiastic support of Gail Wiggett, Brian Berard, and Dennis Kaspereit. This work was performed under the auspices of the U.S. Department of Energy by University of California, Lawrence Livermore National Laboratory under Contract W-7405-Eng-48. 